\title{
Behavioural response of the mud lobster, Thalassina anomala Herbst, 1804 (Decapoda, Gebiidea), to different trapping devices
}

\begin{abstract}
The behavioural response of the mud lobster, Thalassina anomala Herbst, 1804, to different trapping devices (TD), was studied in the mangrove areas of Sibuti, Sarawak, East Malaysia. Nine different TDs were deployed in this study. Observations revealed that there were no differences in response, neither due to the various types of mound, or as a result of the different TDs: rather, the lobsters either avoided, or obstructed those TDs. Detailed observations revealed that the mud lobsters showed skilled avoidance by either moving freshly dug, moist mud into the TD-types made of bamboo and plastic, or moved the fishing net out of the burrow when it was obstructed by such a type of TD. The damaged parts of the mound caused by deployment of the TD were successfully reconstructed or rebuilt by the mud lobster, using moist mud from the bottom of their tunnel. There was no particular period determined, i.e., neither by day nor at night, when the mud lobsters repaired or rebuilt their opened or otherwise disturbed burrows.
\end{abstract}

